\title{
Pam3CSK4 Induces MMP-9 Expression in Human Monocytic THP-1 Cells
}

\author{
Fatema Al-Rashed ${ }^{a}$ Shihab Kochumon ${ }^{a}$ Safa Usmani ${ }^{\text {S Sardar Sindhu }}{ }^{\text {}}$ \\ Rasheed Ahmad ${ }^{\mathrm{a}}$ \\ aImmunology Unit, ${ }^{b}$ Animal and Zebrafish Core Facility, Dasman Diabetes Institute, Kuwait
}

Key Words

Pam3CSK4 • MMP-9 • TLR2 • THP-1 cells

\begin{abstract}
Background: Matrix metalloproteinase (MMP)-9 is known to degrade the extracellular matrix and increased MMP-9 levels are related with the pathogenesis of many inflammatory conditions including obesity. Pam3CSK4 is a synthetic triacylated lipopeptide (LP) which is a potent activator of immune cells and induces cytokine production. However, it is unclear whether Pam3CSK4 is able to induce MMP-9 expression in monocytic cells. We, therefore, determined MMP-9 production by Pam3CSK4-treated THP-1 cells and also investigated the signal transduction pathway(s) involved. Methods: MMP-9 expression was determined by real-time QPCR and ELISA. MMP-9 activity was assessed by zymography. THP-1 cells, THP1$X B_{l u e}{ }^{T M}$ cells, THP1-XBlue ${ }^{T M}$-defMyD cells, anti-TLR2 mAb and selective pharmacological inhibitors were used to study signaling pathways involved. Phosphorylated and total proteins were detected by western blotting. Results: Pam3CSK4 induced MMP-9 expression $(P<0.05)$ at both mRNA and protein levels in human monocytic THP-1 cells. Increased NF-KB/AP-1 activity was detected in Pam3CSK4-treated THP-1 cells and MMP-9 production in these cells was significantly suppressed by pre-treatment with anti-TLR2 neutralizing antibody or by inhibition of clathrin-dependent endocytosis. Also, MyD88-/- THP-1 cells did not express MMP-9 following treatment with Pam3CSK4. Inhibition of JNK, MEK/ERK, p38 MAPK and NF$K B$ significantly suppressed MMP-9 gene expression $(P<0.05)$. Conclusion: Pam3CSK4 induces MMP-9 production in THP-1 cells through the TLR-2/MyD88-dependent mechanism involving MEK/ERK, JNK, p38 MAPK and NF-KB/AP-1 activation.

\section{Introduction}

Matrix metalloproteinases (MMPs) are metal-dependent proteolytic enzymes that degrade components of the extracellular matrix (ECM) [1]. MMP family proteins are involved in important processes such as cell migration, proliferation, and apoptosis [2-4]. So far

F. Al-Rashed and S. Kochumon contributed equally to this work. 
known, five main groups of MMPs include: gelatinases (MMP-2 and MMP-9), collagenases (MMP-1, MMP-8, MMP-13, and MMP-18), stromelysins (MMP-3, MMP-10, and MMP-11), membrane-type MMPs (MMP-14, MMP-15, MMP-16, MMP-17, MMP-24, and MMP-25), and matrilysins (MMP-7 and MMP-26) [5]. The expression and activity of several MMPs have been addressed in many inflammatory disorders including obesity, arthritis, multiple sclerosis, CNS inflammation and cancer [6-10]. MMP-9 is produced by monocytes/macrophages at the sites of chronic inflammation such as arthritic areas, atherosclerosis, and periodontal disease. The expression of MMP-9 by inflammatory or M1-type macrophages exacerbates the inflammatory response by ECM degradation and recruitment of T-helper (Th)-17 cells and neutrophils leading to substantial tissue damage[11, 12]. The activity of MMPs is tightly regulated at levels of gene expression, spatial localization, and proenzyme activation. MMP-9 expression is dependent on the activation of innate immune Toll-like receptors (TLRs) which are pattern recognition receptors highly expressed on immune cells[13]. TLR binding to pathogen-associated molecular patterns (PAMPs) triggers signaling via myeloid differentiation (MyD)-88 downstream adaptor protein to activate a signaling cascade leading to the activation of mitogen-activated protein kinases (MAPKs) and transcription factors (NF- $\kappa \beta$ and AP-1). The activation of transcriptional factors leads to the expression of proinflammatory cytokines as well as MMP production [14-16].

The proinflammatory cytokines TNF- $\alpha$, IL-1 $\beta$, and IL-18 activate MMP-9 gene expression in monocytic cells $[17,18]$. We earlier reported that palmitate, a saturated free fatty acid found in obesity, induced TLR4-dependent activation of MMP-9 gene expression through the mechanism requiring MyD88 recruitment and activation of NF-kB/AP-1 transcription factors [19]. It is well known that bacterial components induce and regulate MMP-9 production in immunocytes. Peptidoglycan, a major cell wall component of gram positive bacteria, increases MMP-9 expression during injury and sepsis [20]. Lipopolysaccharide (LPS), cell wall component of gram negative bacteria, induces several MMPs including MMP-2 and MMP9 in monocytes [21, 22]. We recently found that FSL-1 (Fibroblast-stimulating lipopeptide-1; S-(2, 3 bispalmitoyloxypropyl)-CGDPKHSPKSF) which is a synthetic diacylated lipopeptide mimicking a 44kDa lipoprotein of Mycoplasma salivarium, induced MMP-9 gene expression in monocytic cells through activation of MAPK pathway and the regulatory mechanism involving NF- $\mathrm{kB} / \mathrm{AP}-1$ transcription factors [23]. We earlier reported that heat-killed Listeria monocytogenes (HKLM) activated MMP-9 gene expression in human monocytic THP-1 cells via the activation of TLR2/MAPK/NF- $\kappa$ B pathways [24].

The synthetic bacterial triacylated lipopeptide Pam3-Cys-Ser-Lys4 (Pam3CSK4) is a potent activator of the proinflammatory transcription factor NF- $\kappa$ B. Pam3CSK4 was shown to augment interferon- $\gamma$-induced nitric oxide production in mouse vascular endothelial cells via a physical association between IFN $-\gamma \mathrm{R} \alpha$ and MyD88 [25]. However, the role of Pam3CSK4 in regulating MMP-9 induction in monocytic cells remains to be elucidated. Herein, we show that Pam3CSK4 activates MMP-9 gene expression in THP-1 monocytic cells through the TLR-2/MyD88-dependent mechanism involving activation of MEK1/2 /ERK, JNK, p38 MAPK and NF-кB/AP-1 transcription factors.

\section{Materials and Methods}

\section{Cell Culture}

Human monocytic leukemia THP-1 cell line was purchased from American Type Culture Collection (ATCC) and grown in RPMI-1640 culture medium (Gibco, Life Technologies, Grand Island, USA) supplemented with 10\% fetal bovine serum (Gibco, Life Technologies, Grand Island, NY, USA), 2mM glutamine (Gibco, Invitrogen, Grand Island, NY, USA), 1mM sodium pyruvate, $10 \mathrm{mM}$ HEPES, $100 \mu \mathrm{g} / \mathrm{ml}$ Normocin $50 \mathrm{U} / \mathrm{ml}$ penicillin and $50 \mu \mathrm{g} / \mathrm{ml}$ streptomycin (P/S; (Gibco, Invitrogen, Grand Island, NY, USA), and incubation at $37^{\circ} \mathrm{C}$ (with humidity) in $5 \% \mathrm{CO}_{2}$. THP-1-XBlue cells stably expressing a secreted embryonic alkaline phosphatase (SEAP) reporter inducible by NF- $\kappa$ B and AP-1 were purchased from InvivoGen (InvivoGen, San Diego, CA, USA). THP-1-XBlue ${ }^{\mathrm{TM}}$-defMyD cells (MyD88-/- THP-1 cells) were also purchased from InvivoGen 
(InvivoGen, San Diego, CA, USA). THP-1-XBlue cells were cultured in complete RPMI medium containing Zeocin $(200 \mu \mathrm{g} / \mathrm{ml}$ ) (InvivoGen, San Diego, CA, USA) to select for cells expressing SEAP-NF-kB/AP-1 reporter. THP-1-XBlue ${ }^{\mathrm{TM}}$-defMyD cells were cultured in complete RPMI medium containing Zeocin $(200 \mathrm{ug} / \mathrm{ml})$ and HygroGold $(100 \mu \mathrm{g} / \mathrm{ml}$ ) (InvivoGen, San Diego, CA, USA). Prior to stimulation, THP-1 cells were transferred into normal medium and plated in 12-well plates (Costar, Corning Incorporated, Corning, NY, USA) at $1 \times 10^{6}$ cells/well cell density unless indicated otherwise.

\section{Cell stimulation}

THP-1 cells cultured in 12-well plates (Costar, Corning Incorporated, Corning, NY, USA) at a cell density of $1 \times 10^{6}$ cells/well were stimulated with Pam3CSK4 (InvivoGen, San Diego, CA, USA) (200ng/ml) or TNF- $\alpha$ $(10 \mathrm{ng} / \mathrm{ml})$ for $24 \mathrm{hr}$ at $37^{\circ} \mathrm{C}$. Cells were harvested for RNA isolation and conditioned media were collected and stored at $-80^{\circ} \mathrm{C}$ until use for measuring secretory MMP-9 protein and SEAP activity.

Measurement of NF-KB/AP-1 activity

THP-1 XBlue cells (InvivoGen, San Diego, CA) are THP-1 cells stably transfected with a reporter construct expressing SEAP under the control of a promoter inducible by NF- $\mathrm{KB}$ and AP-1 transcription factors. Following stimulation, NF- $\mathrm{KB}$ and AP-1 are activated and promote the secretion of SEAP in supernatant. THP-1 XBlue cells were stimulated with Pam3CSK4 $(200 \mathrm{ng} / \mathrm{ml})$ or TNF- $\alpha(10 \mathrm{ng} / \mathrm{ml})$ used as a positive control for $24 \mathrm{hr}$ at $37^{\circ} \mathrm{C}$. SEAP levels were detected in conditioned media after $4 \mathrm{hr}$ incubation of supernatants with Quanti-Blue medium (InvivoGen, San Diego, CA, USA) analyzed by ELISA reader at $650 \mathrm{~nm}$ wave length.

\section{Real Time Quantitative RT-PCR}

Total RNA was extracted using RNeasy Mini Kit (Qiagen, Valencia. CA, USA). The cDNA was synthesized using $1 \mu \mathrm{g}$ of total RNA using high capacity cDNA reverse transcription kit (Applied Biosystems, Foster city, CA, USA). For real-time PCR, cDNA template (50ng) was amplified using Inventoried TaqMan Gene Expression Assay products (MMP-9: Hs00234579_m1; GAPDH: Hs03929097_g1) containing two genespecific primers and one TaqMan MGB probe (6-FAM dye-labeled) with a TaqMan $®$ Gene Expression Master Mix (Applied Biosystems, Foster city) and a 7500 Fast Real-Time PCR System (Applied Biosystems, Foster City, CA, USA). The mRNA levels were normalized against GAPDH mRNA and MMP-9 mRNA expression relative to control was calculated using $2^{-\Delta \Delta} \mathrm{Ct}$-method [20]. Relative mRNA expression was shown as fold expression over average of control gene expression. MMP-9 gene expression level in control treatment was taken as 1 and the data were presented as mean \pm SEM values. The results were analyzed statistically and $\mathrm{P}<0.05$ was considered significant.

\section{Quantification of secretory MMP-9}

MMP-9 secreted protein in the supernatants of THP-1 cells stimulated with Pam3CSK4 or TNF- $\alpha$ was quantified using sandwich ELISA following the manufacturer's instructions (R\&D systems, Minneapolis, USA).

\section{Gelatin zymography}

THP-1 cells were incubated with Pam3CSK4 and TNF- $\alpha$. After incubation for $24 \mathrm{hrs,} \mathrm{conditioned}$ media were collected and mixed with Zymogram sample buffer, BioRad (62.5mM Tris-HCl, pH.6.8, 25\% glycerol, $4 \%$ SDS and $0.01 \%$ bromophenol blue) and loaded on to a $10 \%$ polyacrylamide gel with gelatin $(10 \%$ Ready Gel $囚$ Zymogram Gel, Biorad) for electrophoresis. The gel was incubated with renaturing buffer, BioRad (2.5\% Triton X-100) for 1 hour at room temperature and incubated with zymogram developing buffer , BioRad (50mM Tris- $\mathrm{HCl}, \mathrm{pH} 7.5,200 \mathrm{mM} \mathrm{NaCl}$ and $5 \mathrm{mM} \mathrm{CaCl2})$ for $24 \mathrm{hrs}$ at $37^{\circ} \mathrm{C}$. Gels were stained with staining solution (0.5\% Coomassie Brilliant Blue R-250, 40\% Methanol, 10\% Acetic Acid) for 2 hrs and then destained with destaining solution (40\% Methanol, 10\% Acetic Acid) until the bands appeared. Proteolytic activity was indicated as clear bands against the black background of stained gel.

\section{Western blotting}

THP-1 cells were harvested and incubated for 30 min with lysis buffer (Tris $62.5 \mathrm{mM}$ (pH 7.5), 1\% Triton $\mathrm{X}-100,10 \%$ glycerol). The lysates were then centrifuged at $14000 \times \mathrm{g}$ for $10 \mathrm{~min}$ and the supernatants were 
collected. Protein concentration in lysates was measured by Quickstart Bradford Dye Reagent, 1x Protein Assay kit (Bio-Rad Laboratories, Inc, CA). Protein $(20 \mu \mathrm{g})$ samples were mixed with sample loading buffer, heated for $5 \mathrm{~min}$ at $95^{\circ} \mathrm{C}$ and resolved by $12 \%$ SDS-PAGE. Cellular proteins were transferred to ImmunoBlot PVDF membrane (Bio-Rad Laboratories, USA) by electroblotting. The membranes were then blocked with $5 \%$ non-fat milk in PBS for $1 \mathrm{~h}$, followed by incubation with primary antibodies against p-ERK1/2, p-SAPK/JNK, p-p38, p-c-Jun, p-IKK $\alpha / \beta$, p-IKB, p-NF- $\kappa B$ and $\beta$-actin in 1:1000 dilution at $4{ }^{\circ} \mathrm{C}$ overnight. All primary antibodies were purchased from Cell Signaling (Cell Signaling Technology, Inc). The blots were then washed four times with TBS and incubated for $2 \mathrm{~h}$ with HRP-conjugated secondary antibody (Promega, Madison, WI, USA). Immunoreactive bands were developed using an Amersham ECL plus Western Blotting Detection System (GE Health Care, Buckinghamshire, UK) and visualized by Molecular Imager ${ }^{\circledR} \operatorname{VersaDoc}^{\mathrm{TM}}$ MP Imaging Systems (Bio-Rad Laboratories, Hercules, CA, USA).

\section{Statistical analysis}

Statistical analysis was performed using GraphPad Prism software (La Jolla, CA, USA). All data are expressed as mean \pm SEM values. Multiple groups were compared by one-way ANOVA followed by post-hoc Tukey's comparison test. Two groups were compared by unpaired Student's t-test. For all analyses, P-values $<0.05$ were considered significant.

\section{Results}

Pam3CSK4 induces MMP9 expression in the human monocytic THP-1 cells

To determine whether Pam3CSK4 induced MMP-9 expression in monocytic cells, we treated THP-1 cells with $200 \mathrm{ng} / \mathrm{mL}$ of Pam3CSK4 for $24 \mathrm{hrs}$. The data show that Pam3CSK4 induced a significant upregulation of MMP-9 expression at both mRNA (Fig. 1A; $P=0.0021$ ) and protein (Fig. 1B: $P=0.0021$ ) levels. Gelatin zymography of the conditioned media obtained from the cells treated with Pam3CSK4 also showed high level of MMP-9 activity (Fig. 1C).

\section{TLR2 neutralization antibody blocks Pam3CSK4 induced MMP-9 upregulation}

Pam3CSK4 can activate cells through TLR2 and produce inflammatory mediators [25]. Therefore we hypothesized that TLR-2-mediated signaling was involved in MMP-9 production in monocytic THP-1 cells treated with Pam3CSK4. This was accomplished by

Fig. 1. Pam3CSK4 induces MMP-9 expression in human monocytic THP-1 cells. THP-1 cells were treated with the 200ng/mL Pam3CSK4 for 24h. Total cellular RNA was isolated and MMP-9 gene expression was determined by qRT-PCR. Relative mRNA expression was expressed as fold expression over average of gene expression in vehicle-treated cells. The average gene expression level in vehicle-treated cells was assumed to be 1 (A). Cell culture supernatants were used to determine MMP-9 secretory protein by ELISA (B). Gelatin zymography was performed on the conditioned media to analyze MMP-9 activity (C). In all cases, TNF- $\alpha(10 \mathrm{ng} / \mathrm{ml})$ treated THP-1 cells

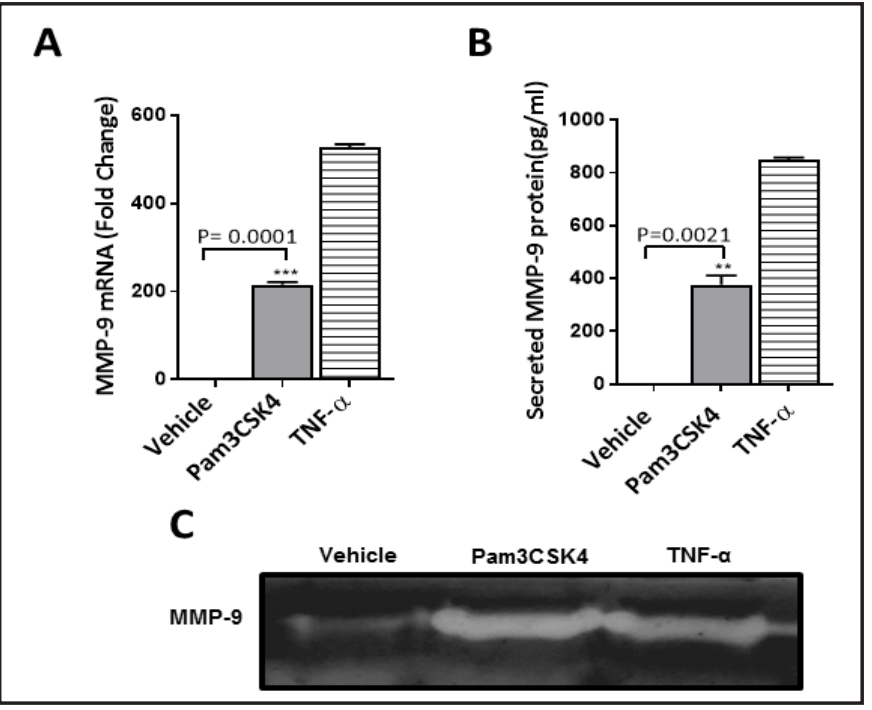
were used as a positive control. Data are represented as mean \pm SEM. Statistical analysis was done using One Way-ANOVA (Tukey's multiple comparisons test). $\mathrm{P}<0.05$ was considered as statistically significant ${ }^{*}$ ), $\mathrm{P}<0.01$ as highly significant $\left(^{* *}\right)$, and $\mathrm{P}<0.001 / \mathrm{P}<0.0001$ were considered as extremely significant $(* * * / * * * *)$. 


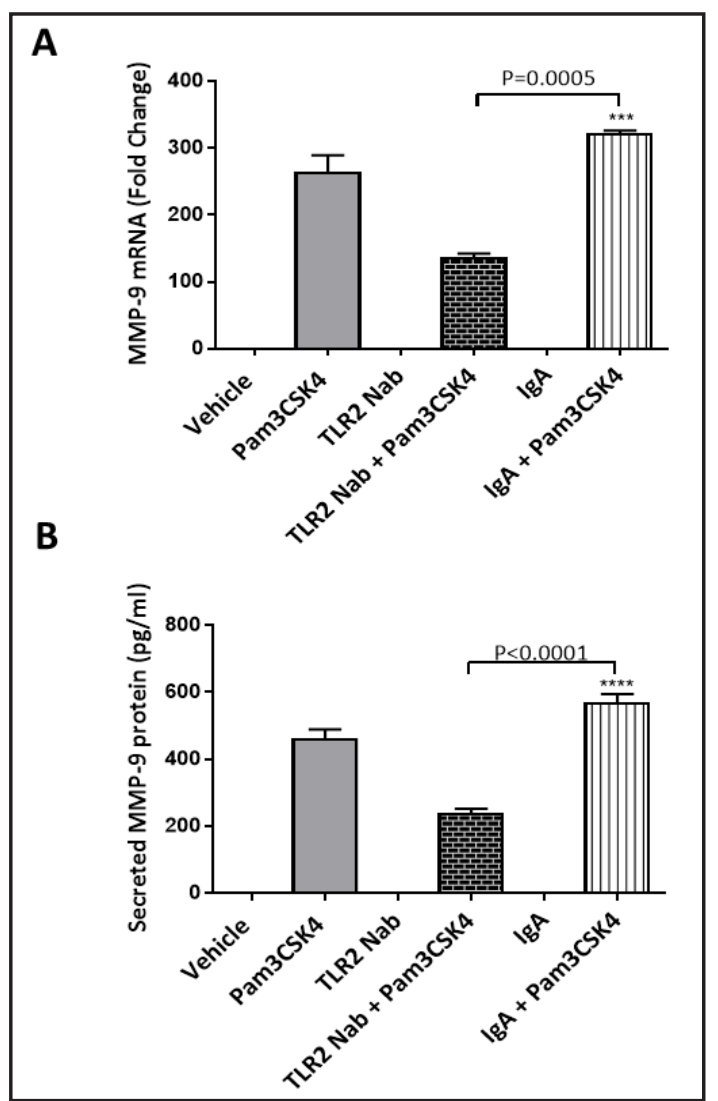

Fig. 2. Pam3CSK4 induced expression of MMP-9 is TLR2 dependent. THP-1 cells were treated with $1 \mu \mathrm{g} / \mathrm{ml}$ of anti-huTLR2-IgA (TLR2 Nab) or isotype-matched control antibody (IgA) for $30 \mathrm{~min}$. Cells were then exposed to Pam3CSK4 (200ng/mL). Cells and conditioned media were collected after 24h. MMP-9 mRNA expression was determined by RT-PCR (A). Secreted MMP-9 protein was assessed by ELISA (B). Data are represented as mean \pm SEM. Statistical analysis was done using One Way-ANOVA (Tukey's multiple comparisons test). $\mathrm{P}<0.05$ was considered as statistically significant $\left({ }^{*}\right), \mathrm{P}<0.01$ as highly significant ${ }^{* *}$ ), and $\mathrm{P}<0.001 / \mathrm{P}<0.0001$ were considered as extremely significant $(* * * / * * * *)$.
A

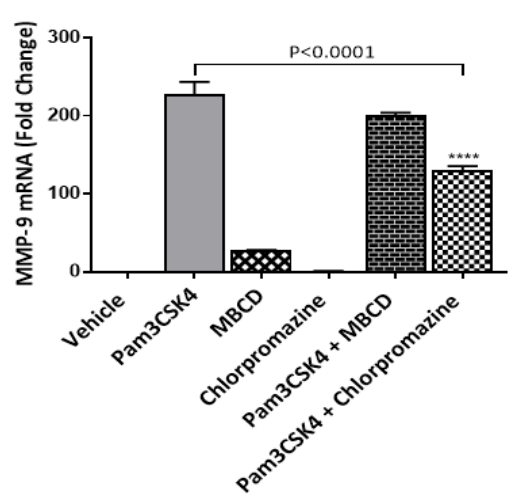

B

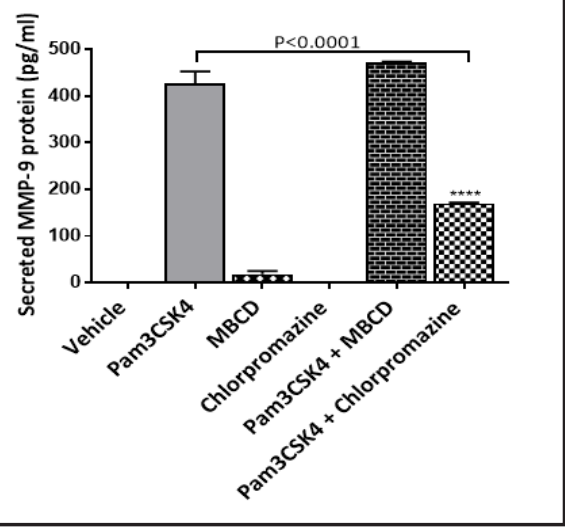

Fig. 3. Pam3CSK4-induced, TLR2-mediated MMP-9 expression in THP-1 cells involves clathrin-dependent endocytosis. THP-1 cell cultures were treated with pharmacological endocytosis inhibitors; chlorpromazine (an inhibitor of clathrin-dependent endocytosis; $10 \mathrm{uM}$ ) and Methyl- $\beta$-cyclodextrin (MBCD; an inhibitor clathrin-independent endocytosis; $2 \mathrm{mM}$ ) for $1 \mathrm{hr}$ prior to treatment with Pam3CSK4 for 24hr [23]. Cells and conditioned media were collected and used for MMP-9 expression. MMP-9 gene expression was determined by real-time RT-PCR (A). Cell culture supernatants were used to determine secreted MMP-9 protein by ELISA (B). Data are represented as mean \pm SEM. Statistical analysis was done using One Way-ANOVA (Tukey's multiple comparisons test). $\mathrm{P}<0.05$ was considered as statistically significant $\left({ }^{*}\right), \mathrm{P}<0.01$ as highly significant $\left({ }^{* *}\right)$, and $\mathrm{P}<0.001 / \mathrm{P}<0.0001$ were considered as extremely significant $(* * * / * * * *)$.

treating cells with TLR-2 blocking antibody and isotype control antibody before stimulation with Pam3CSK4. TLR2 blocking significantly decreased Pam3CSK4-induced MMP-9 gene expression in THP-1 cells (Fig. $2 \mathrm{~A} ; P=0.0005$ ) as well as reduced secreted MMP-9 levels in culture media (Fig. 2B; $P<0.0001$ ).

Effect of endocytosis inhibitor on Pam3CSK4-mediated MMP-9 induction

TLR2-ligand internalization in addition to TLR2-surface binding and receptormediated signaling also plays a role in the activation of inflammatory genes and this process 
Fig. 4. Pam3CSK4-induced MMP-9 expression in THP-1 cells is MyD88-dependent. THP$1-\mathrm{XBlue}^{\mathrm{TM}}$ - defMyD cells were treated with $200 \mathrm{ng} / \mathrm{ml}$ of Pam3CSK4 to induce MMP-9 production. Total cellular RNA was isolated and MMP-9 gene expression was determined by RT-PCR (A). Cell culture supernatants were harvested for ELISA (B). TNF- $\alpha$ (10ng/ $\mathrm{ml}$ ) treated cultures were used as a positive control. Data are represented as mean \pm SEM. Statistical analysis was done using One Way-ANOVA (Tukey's multiple comparisons

A

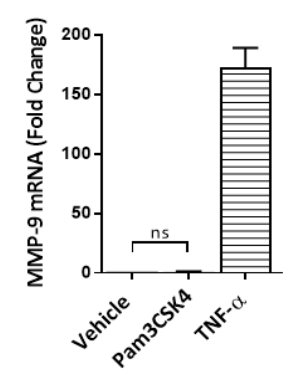

B

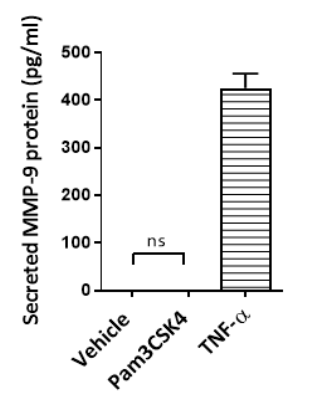
test) $\mathrm{P}<0.0001 . \mathrm{P}<0.05$ was considered as statistically significant $\left({ }^{*}\right), \mathrm{P}<0.01$ as highly significant $(* *)$, and $\mathrm{P}<0.001 / \mathrm{P}<0.0001$ were considered as extremely significant $(* * * / * * *)$.

Fig. 5. Pam3CSK4 treatment of THP-1 cells activates MAPK/NF- $\mathrm{KB}$ signaling pathways. THP-1 cells were treated with Pam3CSK4 for different time points. Cell lysates were prepared as described in methods and samples were run on denaturing gels. Phosphorylated ERK1/2, JNK, p-38 and c-Jun are depicted in the upper panels and respective total proteins are shown in the lower panels (A). Phosphorylated IK$\mathrm{K} \alpha / \beta, \mathrm{IkB}$, and NF- $\mathrm{KB}$ are depicted in the upper panel and $\beta$-actin expression is shown in the bottom panel (B). Total protein expression was used as endogenous control for MAPK and $\beta$-actin was used as endogens control for NF- $\mathrm{KB}$ expression in western blots.

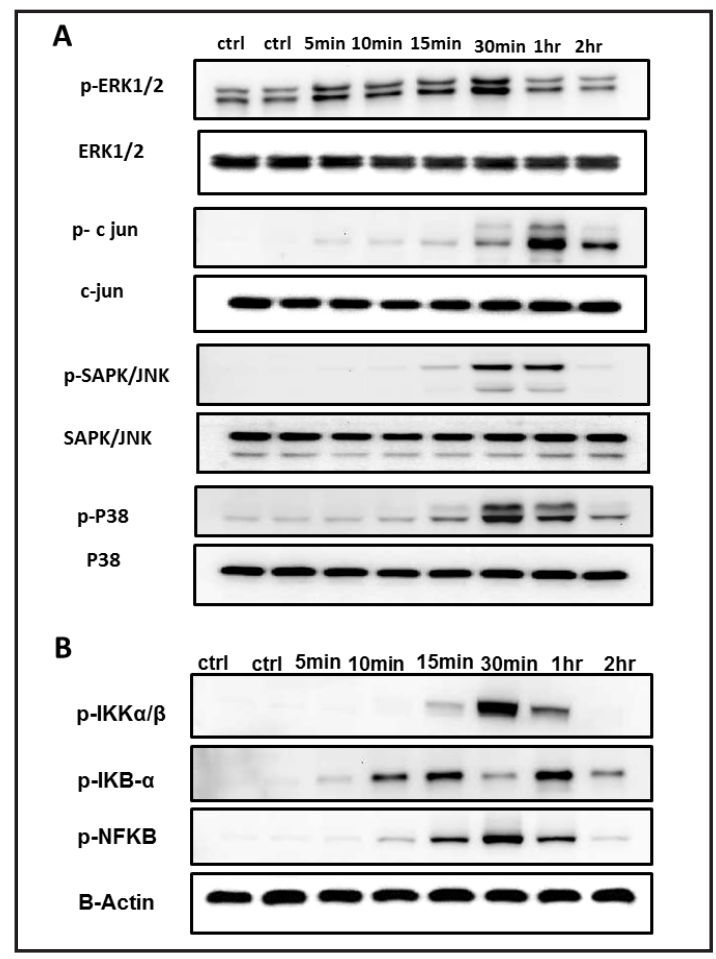

is controlled by clathrin-dependent endocytosis mechanism [26]. Therefore, to assess the role of TLR2-ligand internalization in MMP-9 induction, THP-1 cells were pretreated with $10 \mu \mathrm{M}$ of Chlorpromazine, an inhibitor of clathrin-dependent endocytosis and $1 \mathrm{mM}$ methyl$\beta$-cyclodextrin (MBCD), an inhibitor of clathrin-independent endocytosis followed by treatment with Pam3CSK4 and incubation for $24 \mathrm{hrs}$. The inhibition of clathrin-dependent endocytosis significantly reduced MMP-9 expression both gene (Fig. 3A; p<0.0001) and protein (Fig. 3B, p<0.0001) levels. No significant change was seen in MMP-9 expression in cultures pretreated with $1 \mathrm{mM}$ of MBCD compared to non-MBCD treated controls. These results suggest that TLR2-ligand complex internalization was involved in MMP-9 expression by THP-1 cells treated with Pam3CSK4.

\section{MyD88 deficiency abolishes Pam3CSK4-mediated MMP-9 production}

MyD88 is a central adaptor molecule involved in TLR-mediated signaling regulating the inflammatory mediators' gene expression [27]. To test whether MyD88 was involved in Pam3CSK4-induced MMP-9 expression, THP-1-XBlue ${ }^{\mathrm{TM}}$-defMyD cells, also known as MyD88/- THP-1 cells, which are deficient in MyD88 activity were treated with Pam3CSK4 or TNF- $\alpha$ 
Fig. 6. Pam3CSK4-induced MMP-9 expression in THP-1 cells is abrogated by inhibition of MAPK/NF- $\kappa$ B pathways. THP-1 cells were pretreated with MEKERK inhibitors (U0126: $10 \mu \mathrm{M}$; PD98059: $10 \mu \mathrm{M}$ ) or JNK inhibitor (SP600125: $20 \mu \mathrm{M}$ ) or p38 inhibitor (SB203580: 10 $\mu \mathrm{M}$ ) NF-kB inhibitor (cyclosporine $\mathrm{A} ; 1 \mu \mathrm{M}$ ) for $1 \mathrm{hr}$ and then treated with Pam3CSK4 for 24 hr. Cells and supernatants were collected. Cells were used for the isolation of total RNA to assess the MMP-9 gene expression by real-time RT-PCR (A). Secreted levels of MMP-9 protein were determined in supernatants by ELISA (B). Culture supernatants of X-Blue cells and MyDdef cells were harvested after $24 \mathrm{~h}$ treatments as indicated for assessing SEAP activity indicating the degree of NF-kB/AP-1 activation) (C and D). Data are represented as mean \pm SEM. Statistical analysis was done using One Way-ANOVA (Tukey's multiple comparisons
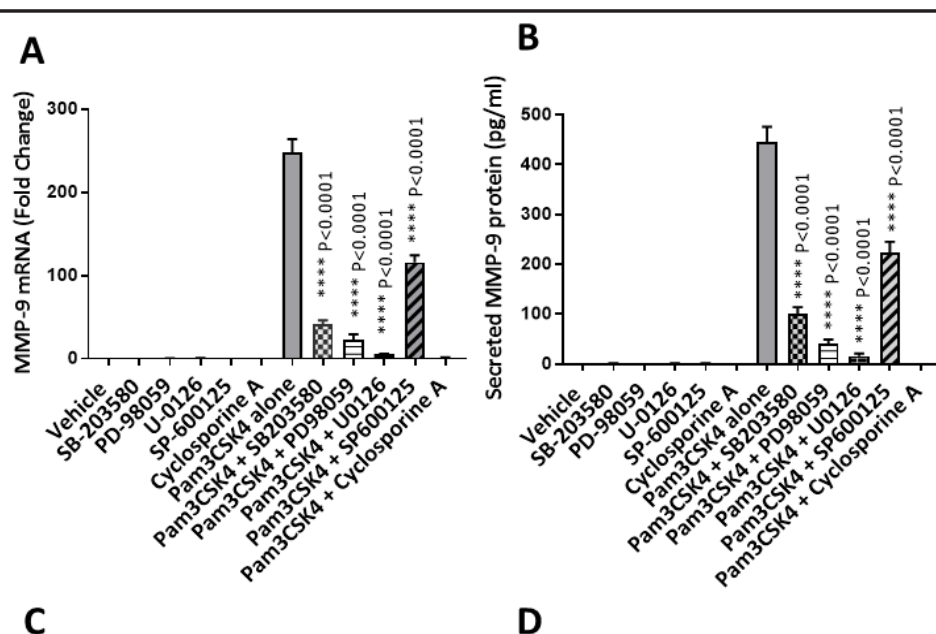

D

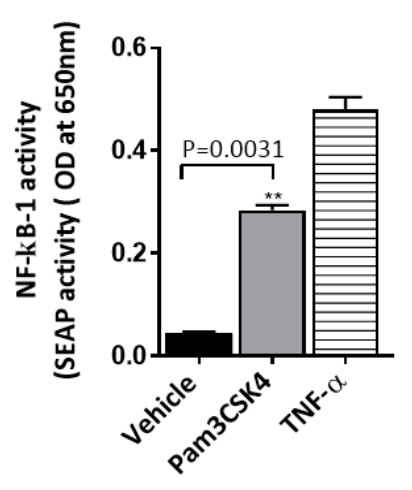
test). $\mathrm{P}<0.0001 . \mathrm{P}<0.05$ was considered as statistically significant $(*), \mathrm{P}<0.01$ as highly significant $\left({ }^{* *}\right)$, and $\mathrm{P}<0.001 / \mathrm{P}<0.0001$ were considered as extremely significant $(* * * / * * * *)$.

(positive control). Following Pam3CSK4 treatment, MMP-9 expression was abrogated in MyD88-/- cells at both mRNA and protein levels (Fig. 4A and B). Nevertheless, TNF- $\alpha-$ mediated induction of MMP-9 was not affected in MyD88-/- cells as it activates MMP-9 gene expression via the MyD88-independent pathway. These data suggest that Pam3CSK4 induces MMP-9 gene upregulation in monocytic cells through the MyD88-dependent signaling cascade.

MAPK and NF-kB signaling pathways are involved in Pam3CSK4-induced MMP-9 upregulation

It has been reported that ERK, JNK, p38, c-Jun, and NF-KB signaling pathways are the downstream activators of TLR2/MyD88. We next asked whether these molecules played a role in Pam3CSK4-induced MMP-9 production. THP-1 cell treatment with Pam3CSK4 increased phosphorylation of ERK, JNK, p38, c-Jun; (Fig 5A) as well as IKK $\alpha / \beta$, IKB and NF- $\kappa B$ (Fig. 5B). As expected, MMP-9 mRNA expression was reduced (Fig 6A; $\mathrm{P}<0.0001$ ) by treatment with inhibitors of either MAPK/JNK (SB203580/SP600125) or ERK (PD98059, U0126) or NF$\kappa \mathrm{B}$ (cyclosporine A). Consistent with qRT-PCR results, MMP-9 levels in culture supernatants of THP-1 cells were significantly suppressed (Fig 6B; $\mathrm{P}<0.0001$ ) after treatment with inhibitors of either MAPKs or NF-kB. Since the promoter of MMP-9 gene has NF- $\mathrm{KB} / \mathrm{AP}-1$ binding sites [28], we investigated whether Pam3CSK4 induced enhanced levels of NF- $\kappa B$ / AP1 activity in THP-1 cells. As expected, NF- $\kappa \mathrm{B} / \mathrm{AP}-1$ activity was strongly induced in culture media from Pam3CSK4-treated cells (Fig. 6C; $\mathrm{P}=0.0031$ ). This confirmed the dependence of Pam3CSK4-induced MMP-9 production on NF-кB/AP1 activation by using THP-1 cells 
expressing a reporter driven by NF- $\mathrm{BB}$ and AP-1 response elements. Similarly, MyD88 deficiency also significantly inhibited the activation of NF- $\mathrm{KB} / \mathrm{AP}-1$ following Pam3CSK4 treatment (Fig. 6D; $\mathrm{P}=0.0197$ ). These data suggest that Pam3CSK4-induced upregulation of MMP-9 gene expression in monocytic cells involves activation of NF- $\mathrm{KB} / \mathrm{AP}-1$ transcription factors through the MyD88-dependent signaling cascade.

\section{Discussion}

MMPs are the major proteases and their dysregulation is involved in the pathogenesis of several pathogensis disorders [29-31]. In obesity, MMP-9 may facilitate the infiltration of immune cells into the adipose tissue and could promote obesity-associated metabolic inflammation. We earlier showed that microbial components and the free fatty acid palmitate induced robust MMP-9 production in monocytic cells $[19,24]$. Bacterial lipoprotein were shown to induce inflammatory mediators including IL-6, TNF- $\alpha$, IL-8, CSF2, CSF3, and ICAM1 and IL-1 $\beta$ [32]. However, the role of bacterial lipoprotein in regulating MMP-9 production in monocytic cells is not defined yet. In this study, we used a synthetic triacylated lipopeptide (Pam3CSK4) that mimics the acylated amino terminus of bacterial lipoprotein. Our data show that Pam3CSK4 induces MMP-9 expression at both mRNA and protein levels in human monocytic THP-1 cells. Moreover, Pam3CSK4-induced MMP-9 production was dependent on the TLR2/MyD88 signaling pathway. TLRs respond to pathogen- or danger-associated molecular patterns by inducing expression of proinflammatory cytokines/chemokines and related inflammatory proteins in monocytes/macrophages and dendritic cells [33]. TLR2/4 were identified as the predominant TLRs that orchestrated the innate immune responses to bacterial infections in a mouse model study through the production of cytokines by macrophages and dendritic cell [34]. Bacterial components such as LPS, lipopeptides, lipoteichoic acids (LTAs), and peptidoglycan stimulate the production of cytokines and other inflammatory mediators [35, 36]. FSL-1 and HKLM were reported to induce MMP9 production [23, 24, 37]. Herein, we show that Pam3CSK4 induces MMP-9 production in monocytic cells. Of note, the production of proinflammatory cytokines depends on both signaling from the cell surface and endosomal compartments [38]. In agreement with this, our data show that blocking the surface TLR-2-mediated signaling by THP-1 cell treatment with anti-TLR2 neutralizing antibody significantly abrogated MMP-9 production in response to Pam3CSK4 activation.

Our data further show that Pam3CSK4-mediated MMP-9 production was regulated by a mechanism that involved clathrin-dependent endocytosis. Together, these results suggest that Pam3CSK4 activation of THP-1 monocytic cells depends on TLR2 signaling both from cell surface and endosomal compartments. TLR signaling pathways are regulated by TIR domain-containing adaptors such as MyD88, TIRAP/Mal, TRIF and TRAM. MyD88 is a key adaptor protein which is common to all TLRs except TLR3 [39]. The interaction between TLR and MyD88 is required for signaling via the MAPK/NF- $\kappa B$ pathways $[16,40]$. Consistent with the requirement of this adaptor protein for TLR response, we show that MyD88 -/- THP-1 cells did not produce MMP-9 following stimulation with Pam3CSK4.

Our data also show that MyD88 is a key regulatory adaptor molecule in Pam3CSK4induced AP-1/NF- $\kappa B$ activation. MMP-9 production was reduced after inhibition of MEK1/2/ ERK, JNK, P38 and NF- $\kappa B$, all of which are known to be involved in MMP-9 production in other cell systems [41-43]. Our data show that the inhibition of MEK/ERK significantly suppressed the MMP-9 production, suggesting that NF- $\kappa B$ and MAPK signaling pathways may have a key role in MMP-9 regulation. The interaction of different ligands with the TLRs has been shown to be involved in MMP-9 production. The free fatty acid palmitate is considered as an endogenous ligand for TLR4 and it induces TLR4-dependent activation of MMP-9 gene expression which requires MyD88 recruitment and activation of NF- $\mathrm{KB} / \mathrm{AP}-1$ transcription factor [19]. Likewise, a microbial component FSL-1 was also shown to trigger MMP-9 production in a TLR-2-dependent manner though the recruitment of MyD88 and 
activation of MEK1/2, ERK 1/2, MEK5/ERK5, JNK, p38 MAPK and NF- $\kappa B / A P-1$ transcription factors [23].

\section{Conclusions}

Taken together, our data show for the first time to our knowledge, that synthetic triacylated lipopeptide Pam3CSK4 induces MMP-9 production in human monocytic THP-1 cells through a TLR-2/MyD88-dependent signaling mechanism that involves activation of MEK1/2/ERK, JNK, p38 MAPK and NF- $\mathrm{B} / \mathrm{AP}-1$ transcription factors.

\section{Abbreviations}

AP-1 (Activator protein 1); ATCC (American Type Culture Collection); ECM (Extracellular matrix); ELISA (Enzyme-linked immunosorbent assay); FAA (Free fatty acid); FSL-1 (Fibroblast-stimulating lipopeptide-1); GAPDH (Glyceraldehyde-3-phosphate dehydrogenase); HKLM (Heat killed Listeria monocytogenes); Pam3CSK4 (Pam3-CysSer-Lys4); LP (Lipopeptide); LPS (Lipopolysaccharide); LTAs (Lipoteichoic acids); MAPK (Mitogen-activated protein kinase); MBCD (Methyl- $\beta$-cyclodextrin); MMP-9 (Matrix metalloproteinase-9); MyD88 (Myeloid differentiation factor 88); NF- $\kappa B$ (Nuclear factorkappaB); PA (Palmitate (palmitic acid)); PAMPs (Pathogen-associated molecular patterns); PBMC (Peripheral blood mononuclear cells); PVDF (Polyvinylidene difluoride membrane); SFA (Saturated fatty acid); SEAP (Secreted embryonic alkaline phosphatase); Th17 (T helper-17); THP-1 (A human monocytic cell line); TIR (Interleukin (IL)-1 receptor called toll-IL1-R); TLRs (Toll-like receptors); TNF- $\alpha$ (Tumor necrosis factor-alpha); TRAM (TRIFrelated adaptor molecule); TRIF (TIR-domain-containing adapter-inducing IFN- $\beta$ ).

\section{Acknowledgments}

This study was financially supported by Kuwait Foundation for the Advancement of Sciences (KFAS). Grant \# RA-2013-002:

\section{Disclosure Statement}

The authors declare that they have no competing interests.

\section{References}

1 Klein T, Bischoff R: Physiology and pathophysiology of matrix metalloproteases. Amino Acids 2011;41:271290.

2 Cao L, Chen C, Zhu H, Gu X, Deng D, Tian X, Liu J, Xiao Q: MMP16 is a marker of poor prognosis in gastric cancer promoting proliferation and invasion. Oncotarget 2016

3 Anghelina M, Schmeisser A, Krishnan P, Moldovan L, Strasser RH, Moldovan NI: Migration of monocytes/ macrophages in vitro and in vivo is accompanied by MMP12-dependent tunnel formation and by neovascularization. Cold Spring Harb Symp Quant Biol 2002;67:209-215.

4 Pardo A, Cabrera S, Maldonado M, Selman M: Role of matrix metalloproteinases in the pathogenesis of idiopathic pulmonary fibrosis. Respir Res 2016;17:23.

5 Nagase H, Visse R, Murphy G: Structure and function of matrix metalloproteinases and TIMPs. Cardiovasc Res 2006;69:562-573.

6 Merdad A, Karim S, Schulten HJ, Dallol A, Buhmeida A, Al-Thubaity F, Gari MA, Chaudhary AG, Abuzenadah AM, Al-Qahtani MH: Expression of matrix metalloproteinases (MMPs) in primary human breast cancer: MMP-9 as a potential biomarker for cancer invasion and metastasis. Anticancer Res 2014;34:1355-1366.

7 Chen Q, Jin M, Yang F, Zhu J, Xiao Q, Zhang L: Matrix metalloproteinases: inflammatory regulators of cell behaviors in vascular formation and remodeling. Mediators Inflamm 2013;2013:928315. 


\section{Cellular Physiology Cell Physiol Biochem 2017;41:1993-2003 \begin{tabular}{l|l} 
and Biochemistry Published onlıne: April13, 2017 & $\begin{array}{l}\text { (c) } 2017 \text { The Author(s). Published by S. Karger AG, Basel } \\
\text { www.karger.com/cpb }\end{array}$
\end{tabular}}

Al-Rashed et al.: Pam3CSK4 Induces MMP-9

8 Chavey C, Mari B, Monthouel MN, Bonnafous S, Anglard P, Van Obberghen E, Tartare-Deckert S: Matrix metalloproteinases are differentially expressed in adipose tissue during obesity and modulate adipocyte differentiation. J Biol Chem 2003;278:11888-11896.

-9 Fu Y, Lei J, Zhuang Y, Zhang K, Lu D: Overexpression of HMGB1 A-box reduced IL-1 $\beta$-induced MMP expression and the production of inflammatory mediators in human chondrocytes. Exp Cell Res 2016;349:184-190.

10 Mishra MK, Yong VW: Myeloid cells - targets of medication in multiple sclerosis. Nat Rev Neurol 2016;12:539-551.

11 Liu W, Zhang X, Zhao M, Zhang X, Chi J, Liu Y, Lin F, Fu Y, Ma D, Yin X: Activation in M1 but not M2 Macrophages Contributes to Cardiac Remodeling after Myocardial Infarction in Rats: a Critical Role of the Calcium Sensing Receptor/NRLP3 Inflammasome. Cell Physiol Biochem 2015;35:2483-2500.

12 Cao Q, Harris DC, Wang Y: Macrophages in kidney injury, inflammation, and fibrosis. Physiology 2015;30:183-194.

13 Medzhitov R, Shevach EM, Trinchieri G, Mellor AL, Munn DH, Gordon S, Libby P, Hansson GK, Shortman K, Dong C, Gabrilovich D, Gabryšová L, Howes A, O'Garra A: Highlights of 10 years of immunology in Nature Reviews Immunology. Nat Rev Immunol 2011;11:693-702.

14 Akira S, Takeda K: Toll-like receptor signalling. Nat Rev Immunol 2004;4:499-511.

15 Kawai T, Akira S: The role of pattern-recognition receptors in innate immunity: update on Toll-like receptors. Nat Immunol 2010;11:373-384.

-16 Kerscher B, Dambuza IM, Christofi M, Reid DM, Yamasaki S, Willment JA, Brown GD: Signalling through MyD88 drives surface expression of the mycobacterial receptors MCL (Clecsf8, Clec4d) and Mincle (Clec4e) following microbial stimulation. Microbes Infect 2016;18:505-509.

17 Ghosh A, Pechota LV, Upchurch GR, Eliason JL: Cross-talk between macrophages, smooth muscle cells, and endothelial cells in response to cigarette smoke: the effects on MMP2 and 9. Mol Cell Biochem 2015;410:75-84.

18 Shinagawa H, Frantz S: Cellular immunity and cardiac remodeling after myocardial infarction: role of neutrophils, monocytes, and macrophages. Curr Heart Fail Rep 2015;12:247-254.

19 Sindhu S, Al-Roub A, Koshy M, Thomas R, Ahmad R: Palmitate-Induced MMP-9 Expression in the Human Monocytic Cells is Mediated through the TLR4-MyD88 Dependent Mechanism. Cell Physiol Biochem 2016;39:889-900.

20 Wray GM, Foster SJ, Hinds CJ, Thiemermann C: A cell wall component from pathogenic and non-pathogenic gram-positive bacteria (peptidoglycan) synergises with endotoxin to cause the release of tumour necrosis factor-alpha, nitric oxide production, shock, and multiple organ injury/dysfunction in the rat. Shock 2001;15:135-142.

21 Wang YY, Myhre AE, Pettersen SJ, Dahle MK, Foster SJ, Thiemermann C, Bjørnland K, Aasen AO, Wang JE: Peptidoglycan of Staphylococcus aureus induces enhanced levels of matrix metalloproteinase-9 in human blood originating from neutrophils. Shock 2005;24:214-218.

-22 Yang YH, Li DL, Bi XY, Sun L, Yu XJ, Fang HL, Miao Y, Zhao M, He X, Liu JJ, Zang WJ: Acetylcholine Inhibits LPS-Induced MMP-9 Production and Cell Migration via the alpha7 nAChR-JAK2/STAT3 Pathway in RAW264.7 Cells. Cell Physiol Biochem 2015;36:2025-2038.

-23 Ahmad R, Shihab PK, Jasem S, Behbehani K: FSL-1 induces MMP-9 production through TLR-2 and NF- $\mathrm{\kappa B} /$ AP-1 signaling pathways in monocytic THP-1 cells. Cell Physiol Biochem 2014;34:929-942.

24 Shihab PK, Al-Roub A, Al-Ghanim M, Al-Mass A, Behbehani K, Ahmad R: TLR2 and AP-1/NF-kappaB are involved in the regulation of MMP-9 elicited by heat killed Listeria monocytogenes in human monocytic THP-1 cells. J Inflamm (Lond) 2015;12:32.

25 Tsolmongyn B, Koide N, Jambalganiin U, Odkhuu E, Naiki Y, Komatsu T, Yoshida T, Yokochi T: A Toll-like receptor 2 ligand, Pam3CSK4, augments interferon- $\gamma$-induced nitric oxide production via a physical association between MyD88 and interferon- $\gamma$ receptor in vascular endothelial cells. Immunology 2013;140:352-361.

-26 Shamsul HM, Hasebe A, Iyori M, Ohtani M, Kiura K, Zhang D, Totsuka Y, Shibata K: The Toll-like receptor 2 (TLR2) ligand FSL-1 is internalized via the clathrin-dependent endocytic pathway triggered by CD14 and CD36 but not by TLR2. Immunology 2010;130:262-272.

27 Brown J, Wang H, Hajishengallis GN, Martin M: TLR-signaling networks: an integration of adaptor molecules, kinases, and cross-talk. J Dent Res 2011;90:417-427. 


\section{Cellular Physiology Cell Physiol Biochem 2017;41:1993-2003 \begin{tabular}{l|l} 
DOI: 10.1159/000475298 & $\begin{array}{l}\text { O 2017 The Author(s). Published by S. Karger AG, Basel } \\
\text { www.karger.com/cpb }\end{array}$
\end{tabular}}

Al-Rashed et al.: Pam3CSK4 Induces MMP-9

28 Ray A, Bal BS, Ray BK: Transcriptional induction of matrix metalloproteinase-9 in the chondrocyte and synoviocyte cells is regulated via a novel mechanism: evidence for functional cooperation between serum amyloid A-activating factor-1 and AP-1. J Immunol 2005;175:4039-4048.

29 Bramwell KK, Mock K, Ma Y, Weis JH, Teuscher C, Weis JJ: $\beta$-Glucuronidase, a Regulator of Lyme Arthritis Severity, Modulates Lysosomal Trafficking and MMP-9 Secretion in Response to Inflammatory Stimuli. J Immunol 2015;195:1647-1656.

-30 Silosi I, Cojocaru M, Foia L, Boldeanu MV, Petrescu F, Surlin P, Biciusca V: Significance of circulating and crevicular matrix metalloproteinase-9 in rheumatoid arthritis-chronic periodontitis association. J Immunol Res 2015;2015:218060.

-31 Castellazzi M, Bellini T, Trentini A, Delbue S, Elia F, Gastaldi M, Franciotta D, Bergamaschi R, Manfrinato MC, Volta CA, Granieri E, Fainardi E: Serum Gelatinases Levels in Multiple Sclerosis Patients during 21 Months of Natalizumab Therapy. Dis Markers 2016;2016:8434209.

-32 Wilhelmsen K, Mesa KR, Prakash A, Xu F, Hellman J: Activation of endothelial TLR2 by bacterial lipoprotein upregulates proteins specific for the neutrophil response. Innate Immun 2012;18:602-616.

33 Takeda K, Akira S: Toll-like receptors. Curr Protoc Immunol 2015;109:14.12.11-10.

34 Stenzel W, Soltek S, Sanchez-Ruiz M, Akira S, Miletic H, Schlüter D, Deckert M: Both TLR2 and TLR4 are required for the effective immune response in Staphylococcus aureus-induced experimental murine brain abscess. Am J Pathol 2008;172:132-145.

-35 Kim SH, Kang YJ, Kim WJ, Woo DK, Lee Y, Kim DI, Park YB, Kwon BS, Park JE, Lee WH: TWEAK can induce pro-inflammatory cytokines and matrix metalloproteinase-9 in macrophages. Circ J 2004;68:396-399.

-36 Lee Y, Kim H, Kim S, Kim KH, Chung JH: Activation of toll-like receptors 2, 3 or 5 induces matrix metalloproteinase- 1 and -9 expression with the involvement of MAPKs and NF-kappaB in human epidermal keratinocytes. Exp Dermatol 2010;19:e44-49.

-37 Lim R, Barker G, Lappas M: The TLR2 ligand FSL-1 and the TLR5 ligand Flagellin mediate proinflammatory and pro-labour response via MyD88/TRAF6/NF-кB-dependent signalling. Am J Reprod Immunol 2014;71:401-417.

-38 Kagan JC, Su T, Horng T, Chow A, Akira S, Medzhitov R: TRAM couples endocytosis of Toll-like receptor 4 to the induction of interferon-beta. Nat Immunol 2008;9:361-368.

39 Takeda K, Akira S: TLR signaling pathways. Semin Immunol 2004;16:3-9.

40 Piao W, Ru LW, Toshchakov VY: Differential adapter recruitment by TLR2 co-receptors. Pathog Dis 2016;74

41 Cho HJ, Kang JH, Kwak JY, Lee TS, Lee IS, Park NG, Nakajima H, Magae J, Chang YC: Ascofuranone suppresses PMA-mediated matrix metalloproteinase-9 gene activation through the Ras/Raf/MEK/ERK- and Ap1dependent mechanisms. Carcinogenesis 2007;28:1104-1110.

-42 Tseng HC, Lee IT, Lin CC, Chi PL, Cheng SE, Shih RH, Hsiao LD, Yang CM: IL-1 $\beta$ promotes corneal epithelial cell migration by increasing MMP-9 expression through NF- $\mathrm{KB}$ - and AP-1-dependent pathways. PLoS One 2013;8:e57955.

-43 Wang QM, Wang H, Li YF, Xie ZY, Ma Y, Yan JJ, Gao YF, Wang ZM, Wang LS: Inhibition of EMMPRIN and MMP-9 Expression by Epigallocatechin-3-Gallate through 67-kDa Laminin Receptor in PMA-Induced Macrophages. Cell Physiol Biochem 2016;39:2308-2319. 